\title{
LECTURA DE TEXTOS HISTÓRICOS EN EL AULA
}

\author{
John A. Fossa \\ jfossa03@gmail.com \\ Universidade Estadual da Paraíba
}

Recibido: 05/11/2019 Aceptado: 20/01/2020

\begin{abstract}
Resumen
Después de aclarar algunas ambigüedades terminológicas, aquí hay dos argumentos relacionados con la lectura de textos históricos en el aula. El primer argumento parte de la premisa de que las matemáticas son una parte importante de la cultura general de la humanidad en el sentido de que impregna casi cualquier otra parte de esa cultura. Sin embargo, uno de los principales objetivos de la educación es la apropiación de esa cultura para que el estudiante pueda lograr una vida rica y satisfactoria. Como resultado, el estudiante debe tener contactos directos e intensos con textos históricos que son grandes expresiones de esta cultura. El segundo argumento parte de una caracterización del conocimiento como una relación dialéctica tripartita entre el individuo, el otro y el mundo. Por lo tanto, enfrentamos el conocimiento como una actividad constructiva realizada por el individuo, pero desarrollada dentro de una comunidad social, antes que un objeto. Luego muestra cómo la lectura de textos históricos en el aula contribuye a cada uno de estos aspectos del conocimiento para ayudar a lograr un verdadero conocimiento matemático.
\end{abstract}

Palabras clave: Historia y Educación Matemática; fuentes historicas; apropriación de conocimiento matemático.

\section{READING HISTORICAL TEXTS IN THE CLASSROOM}

\begin{abstract}
After clarifying some ambiguous terminology, two arguments related to the reading of historical texts in the mathematics classroom are herein presented. The first argument starts from the premise that mathematics is a very important part of human culture in general, in that it permeates almost all of the other parts of this culture. But one of the principle objectives of education is the appropriation of this very culture, so that the student may be enabled to lead a full and satisfying life. In consequence, the student should have intense direct contacts with historical texts that are prominent expressions of this culture. The second argument starts from a characterization of knowledge as a tripartite dialectical relation among the individual, the other and the world. Thus, we are confronted with knowledge as being a constructive activity performed by an individual, but developed within a social context, in face of an object. It is then shown how the reading of historical texts in the mathematics classroom contributes, with regard to each of these aspects of knowledge, to the building up of genuine mathematical knowledge.
\end{abstract}


Keywords: History in Mathematics Education; historical texts; appropriation of mathematical knowledge.

\title{
LENDO TEXTOS HISTÓRICOS NA SALA DE AULA
}

\begin{abstract}
Resumo
Depois de esclarecer algumas ambiguidades de terminologia, apresenta-se aqui dois argumentos relacionados à leitura de textos históricos na sala de aula. $\mathrm{O}$ primeiro argumento parte da premissa de que a matemática é uma parte importante da cultura geral da humanidade no sentido de que ela permeia quase todas as outras partes dessa cultura. Mas, um dos principais objetivos da educação é a apropriação da referida cultura para que o educando possa alcançar uma vida rica e satisfatória. Em consequência, o aluno deveria ter contatos diretos e intensos com textos históricos que são grandes expressões dessa cultura. O segundo argumento parte de uma caracterização do conhecimento como sendo um relacionamento dialético tripartido entre o indivíduo, o outro e o mundo. Assim, deparamos com o conhecimento como uma atividade construtiva feita pelo indivíduo, mas desenvolvida dentro de uma comunidade social, perante um objeto. Mostra-se, então, como a leitura de textos históricos na sala de aula contribui com cada um desses aspectos do conhecimento para ajudar na consecução de conhecimento matemático genuíno.
\end{abstract}

Palavras-chave: História e Educação Matemática; fontes históricas; apropriação de conhecimento matemático.

Nos últimos anos, a história da matemática vem conquistando um lugar importante como um agente de cognição na Educação Matemática. A conquista é, de fato, bastante merecida, pois a história é um instrumento muito versátil para o ensino da referida matéria. Antes, em contraste, a história da matemática foi limitada a ações motivadoras e essa limitação foi muito criticada por quem almejava um papel mais arrojada para a história. Embora compartilhamos com estes a aspiração para um uso mais dinâmico da história da matemática no ensino da matemática, devemos registrar aqui o fato de que avaliamos o potencial da história como fonte de motivação como sendo altamente importante. Essa nossa avaliação parte do princípio construtivista de que o aluno deve construir por si mesmo (o que, aliás, não significa por si só!) seu conhecimento e que isso não será feito na ausência de motivação adequada. Isto dito, porém, voltaremos a nossa atenção agora para usos da história que participam na construção do conhecimento.

Entre os vários papeis que a história desempenha para favorecer a construção do conhecimento matemático, dois, ao nosso ver, são preeminentes. O primeiro é a utilização da história da matemática para informar atividades construtivistas. O presente autor, junto com vários dos seus alunos de pós-graduação, tem desenvolvido pesquisas nessa área desde os 
meados da década dos 90s (veja Fossa, 1998). Um exemplo de como proceder usando o referido enfoque pode ser achado em Fossa (2006). O segundo dos referidos papeis é o uso de textos históricos na sala de aula, que passaremos a investigar a seguir.

\section{Textos Históricos}

Visto que há algumas pequenas confusões na literatura sobre o presente assunto, faremos aqui uns breves esclarecimentos. Em primeiro lugar, por 'texto', ou alternativamente, 'fonte', queremos dizer, pelos propósitos do presente trabalho, qualquer documento preservado em alguma média. Na grande maioria dos casos do nosso interesse, tratar-se-á de documentos impressos ou digitalizados.

Dado a caracterização contida no parágrafo anterior, a palavra 'texto' não equivale à expressão 'livro texto', ou seja, um documento elaborado expressamente para fins didáticos, pois este é apenas uma parte daquele. Mesmo assim, o conceito de 'livro texto' não é tão nítido quanto possa aparecer. O Papiro de Rhind ${ }^{1}$ (Papiro de Ahmes), por exemplo, poderá ser considerado um livro texto, ou pelo menos algo análogo aos nossos livros textos na cultura do Egito Antigo, visto que foi elaborado para a instrução dos escribas. Em contraste, os três artigos de Leonhard Euler, todos com o mesmo título, De numeris amicabilibus ${ }^{2}$, são claramente relatos de pesquisa em matemática. Mas, como devemos categorizar o Tractatus de numerorum doctrina capita sedecim, quae supersunt ${ }^{3}$, do mesmo Euler, que inicia com explicações das mais básicas e posteriormente acaba apresentando resultados da sua pesquisa? Visto que o próprio Euler não nos disse (é um texto póstumo, inacabado e sem prefácio), não sabemos com certeza. Pior ainda, Os Elementos ${ }^{4}$ de Euclides provavelmente foi escrito como um tratado matemático, mas eventualmente se tornou um livro texto, às vezes, porém, apenas parcialmente - por muito tempo o aluno era esperado dominar Os Elementos só até o pons asinorum (Propsição 5 do Livro I)!

Felizmente, podemos abstrair dessas questões historiográficas, pois qualquer documento, seja ele um livro texto, um relato de pesquisa, ou um híbrido, poderá ser

\footnotetext{
${ }^{1}$ Ver The Rhind Mathematical Papyrus (1927).

${ }^{2}$ Ver Euler (1774, 1750 e 1849) e, em português, Euler (2017a).

${ }^{3}$ Ver Euler (1849), em português, Euler (2017), e, em inglês, Euler (2019).

${ }^{4}$ Ver, em inglês, Euclid (1956), e, em português, Euclides (2009).
} 
contemplado como um recurso pedagógico e usado na sala de aula. Logo, usaremos a palavra 'texto', ou como já indicamos 'fonte', no sentido generalizado, apontado acima.

Por 'texto original', ou alternativamente 'fonte original', queremos dizer qualquer documento, ou cópia de documento, que não tem passado por modificações significativas. Quando o documento é oriundo do passado, seja ela original, seja modificado, usaremos o termo 'texto histórico', ou alternativamente, 'fonte histórica'.

$\mathrm{Na}$ caracterização de 'texto histórico', há duas imprecisões que não, aliás, requerem delineações exatas, mas merecem ser elaboradas um pouco mais. A primeira é a questão da sua localização no tempo, pois ontem, por exemplo, é no passado, mas não parece razoável (na maioria dos casos) chamar um livro publicado ontem um texto histórico. Consideremos, por exemplo os Elementos de Cálculo Diferencial e Integral de William Anthony Granville e Percey F. Smith, publicado originalmente em 1904, mas reeditados várias vezes e traduzidos para o português em $1954 .^{5}$ Embora esse texto foi usado até bem recentemente, o fato de que foi descontinuado, porque é considerado "ultrapassado", é o suficiente para considera-lo um texto histórico. ${ }^{6}$ A segunda imprecisão se diz referente aos tipos de modificações que podem ser feitas numa fonte original que nos levam a passar a considera-lo um texto histórico, nãooriginal. Basicamente, pensamos aqui em modificações no próprio texto, como simplificações de linguagem, modificação da ordem de apresentação dos tópicos do texto e traduções.

É a questão da tradução que é mais polêmica. De um ponto de vista prática, porém, traduções são necessários para fazer a maioria dos textos acessíveis ao aluno. Ainda mais, embora seja imprescindível que um pesquisador consulta o texto original, uma boa tradução é suficiente para os propósitos pedagógicos e insistir no contrário seria pura pedantismo. Mesmo assim, em alguns casos, textos em línguas estrangeiras - com destaque aos textos em inglês ou francês - podem estar ao alcance do aluno, especialmente se trata de pequenos trechos abordados conjuntamente com o professor de línguas.

Finalmente, entendemos a frase 'na sala de aula' a ser aplicável a qualquer situação didática, mesmo se não ocorre no espaço físico da sala de aula da escola. Assim, incluímos tais coisas como projetos a serem feitos pelo aluno, ou individualmente ou em grupos, em casa, com relatórios entregados ao professor.

\footnotetext{
${ }^{5}$ Ver Granville e Smith (1904) e, em português, Granville, Smith e Longley (1961).

${ }^{6}$ Por uma análise desse texto e seu valor pedagógico, ver Almeida (a aparecer).
} 
Aqui consideraremos apenas dois argumentos para o uso de textos históricos na sala de aula, pois, do ponto de vista do presente autor, são não somente os dois principais argumentos, mas também são os dois que são geralmente esquecidos. O primeiro é centrado no fato de que a matemática faz parte da herança cultural do homem e, assim, fontes históricas deveriam ter um lugar de destaque no currículo escolar. O segundo depende de uma análise da natureza do conhecimento como uma dialética tripartida entre o indivíduo, o outro e o mundo e mostra como a leitura de textos históricas na sala de aula promova a construção do conhecimento.

\section{Matemática como Herança Cultural}

A matemática não é uma entidade que pode ser achada no mundo natural, nem um atributo inerente a tais entidades. Muito pelo contrário, é um produto cultural inventado pelo espírito humano. Nesse sentido, não é diferente das ciências ou das artes. Assim, da mesma forma em que é necessário ter, para assegurar uma educação que promove uma vida plena para o educando, certa convivência com as ciências e as artes, é necessário ter certa convivência com a matemática e seu desenvolvimento perante a história. Isto é, a apropriação da herança cultural do homem é a forma em que o homem realiza suas potencialidades humanas como um ser humano, alcança uma vida feliz e contribui para o desenvolvimento continuado da própria cultura em que ele está inserido. Mas, desde que a matemática é uma parte importante dessa cultura, é imprescindível que o homem apropria a matemática para que possa realizar suas potencialidades humanas. ${ }^{7}$

É inegável que parte do que queremos dizer por apropriação da matemática é a habilidade de pensar matematicamente e desenvolver vários procedimentos matemáticos com certa desenvoltura. Nesse sentido, a comparação com as habilidades linguísticas será instrutiva, pois parte do que queremos dizer pela apropriação da língua é a habilidade de produzir comunicações eficazes orais e escritas, bem como entender as comunicações de outros. A palavra, no entanto, contempla não somente o verdadeiro, mas também o belo. Assim, não ficamos satisfeitos apenas com a mera aquisição das habilidades linguísticas, mas insistimos em ter contato com grandes produções linguísticas da nossa herança cultural. O mesmo

\footnotetext{
${ }^{7}$ A matemática é uma atividade humana e, assim, uma invenção humana. Como veremos mais adiante na discussão do conhecimento, porém, o objeto matemático não é uma pura invenção humana. Também traçaremos, no mencionado lugar, considerações mais precisas sobre o conceito de 'apropriação'.
} 
acontece com a matemática: o aluno deveria ter contato direto com grandes produções matemáticas que fazem parte da nossa evolução cultural.

Devemos elaborar esse ponto mais um pouquinho. Não é de muito serventia, exceto para fins de alimentar a rapacidade da indústria de testagens escolares (pois hesito dizer, nesse contexto, "avaliação"), que o aluno saiba, por exemplo, que José de Alencar era uma das nossas maiores expressões do indianismo do século XIX, sem nunca ter lido, por exemplo, $O$ Guarani. É necessário que o aluno tenha contato com o próprio livro, indagando-o heuristicamente, dialogando com as ideias nele contidas e apreciando-o como uma obra literária. Da mesma forma, não é o suficiente que o aluno conhece alguns fatos sobre a história da matemática sem ter qualquer contato com obras provenientes daquela história. Precisa-se indagar heuristicamente o texto histórico, dialogar com as ideias nele contidas e apreciá-lo como um texto matemático. Isto foi explicitamente reconhecido pelos criadores do currículo liberal das Grandes Obras da Civilização Ocidental ${ }^{8}$, um currículo que se baseia inteiramente na leitura de fontes históricas de vários campos de estudo. Entre os textos dos 74 autores incluídos no programa, há textos matemáticos de Euclides, Arquimedes, Apolônio de Perga, Nicômaco de Gerasa, René Descartes, Blaise Pascal e Isaac Newton. Claramente, textos destes autores, bem com várias obras de outros matemáticos, são textos clássicos que merecem ser conhecidos pelo público geral.

\section{A Ubiquidade da Matemática}

Evidentemente, o argumento exposto na seção anterior se aplica a virtualmente todos os campos de investigação que tem sido desenvolvido pelo homem. Em consequência, o educador teria de enfrentar um grande problema referente à sobrecarga de um currículo escolar que já tem uma abundância descomedida de informação com que assola o aluno. Destarte, precisamos reconhecer a necessidade de incluir leituras de fontes históricas de muitas áreas diferentes e, ao mesmo tempo, reconciliar isto com as limitações inevitáveis do currículo escolar. Uma maneira de conseguir a referida reconciliação é fazer com que as leituras de textos históricos sejam incorporadas como uma parte integral do ensino das várias disciplinas. Voltaremos a isto, em relação ao ensino da matemática, mais adiante. Mas, mesmo

\footnotetext{
${ }^{8}$ Ver Adler (1961).
} 
lançando mão e esse expediente, permanecerá o imperativo de fazer uma hierarquização de escolhas referente à estruturação do currículo.

Parece, de fato, inegável que a base de toda a educação é a apropriação da linguagem. Isso se fundamenta no simples fato de que toda a comunicação, ou pelo menos a comunicação raciocinativa, inclusive a da matemática, depende da linguagem. É notável, porém, que a ubiquidade da linguagem dentro da cultura humana é quase alcançada pela ubiquidade da matemática, pois procedimentos matemáticos e/ou pensamentos matemáticos permeiam as realizações culturais do homem de forma ímpar, frequentemente, até, em maneiras não geralmente reconhecidas. Sendo isso o caso, temos fortes razões para privilegiar a apropriação de textos históricos matemáticos. Assim, passaremos em revista, de forma breve, algumas das principais maneiras em que a matemática está presente em outras partes da cultura humana.

Em primeiro lugar, é notório o papel da matemática nas ciências e na tecnologia. $\mathrm{Na}$ verdade, a matematização das ciências tem raízes históricas bastante compridas, mas o processo se intensificou com o desenvolvimento do cálculo infinitesimal e, em especial, com o uso de equações diferenciais para modelar situações do mundo físico. Os sucessos iniciais levaram a um relacionamento sempre mais estreito entre a matemática e as ciências, resultando, por exemplo, no fato de que a física teórica e partes da matemática aplicada são, hoje em dia, virtualmente indistinguíveis. Mas, não foi apenas as ciências físicas que foram afetadas pela matemática, pois as ciências biológicas, bem como as ciências sociais, também foram transformadas por vários ramos da matemática, da matemática discreta ao mesmo cálculo que foi tão transformativo nas ciências físicas. Nas ciências sociais e nas ciências relacionadas à saúde e à medicina, porém, a influência mais forte talvez tenha sido a da estatística, pois foi a possibilidade proferida por essa teoria matemática de detectar possíveis relações de causa e efeito e/ou correlações importantes que permitiu o enorme crescimento dessas ciências.

Ao voltar a nossa atenção para a influência da matemática sobre a arte, pensamos quase imediatamente no desenvolvimento, no Renascimento, das técnicas da perspectiva e sua ligação com a geometria projetiva. A referida influência, porém, não tem sido tão limitada, nem no espaço, nem no tempo, como foi documentada, por exemplo, em Gamwell (2016) e Hofstadter (1980). De fato, essas publicações não somente documentam a influência da matemática nas esferas artísticas, mas atestam como a matemática está presente de forma 
preeminente na intricada melodia de ideias que constitui a criação artística. Mas, nem precisamos nos limitar ao mundo dos "grandes artistas" para ver a presença da matemática na arte, pois investigações etnomatemáticas, a exemplo das de Joseph (1991), tem mostrado essa presença nas expressões culturais mais "populares". Ainda no campo artística, visto que o ritmo, por exemplo, depende da contagem, a presença da matemática na música não deve ser surpreendente. Não obstante, a influência da matemática sobre esse ramo da arte é consideravelmente mais ampla, como mostra Abdounur (2002). Ainda outra expressão artística frequentemente informada pela matemática é a da literatura. Muitas vezes, essa influência, especialmente dentro da vasta tradição pitagórica, é aliada com a astronomia (considerada como parte da matemática na época) como Fossa e Erickson (2014) ilustra com o conceito de alegoria matemática como um elemento estrutural de obras literárias.

Grugnetti e Rogers (2000) apontam para as supostas propriedades místicas e religiosas de várias formas geométricas, bem como tais conceitos como a infinidade, como manifestações da influência da matemática na filosofia. Quando lembramos, porém, que um número expressivo de filósofos era também matemáticos, ou receberam treinamento na matemática, podemos desconfiar de que a avaliação de Grugnetti e Rogers seja um tanto tímida. De fato, Erickson e Fossa (2006) mostra que a matemática estruturou a filosofia platônica e ainda que ela foi determinante no pensamento de vários outros filosóficos. Parsons (1983) aborda a matemática no pensamento de Immanuel Kant (1724-1804) e nos filósofos analíticos contemporâneos, enquanto Hill (2002) faz o mesmo em relação à fenomenologia de Edmund Husserl (1859-1938). Mais ainda, é notório que novas descobertas na matemática têm sempre ocasionado novas teorias filosóficas e Fossa (2019) mostrou como as duas disciplinas têm se desenvolvido de forma paralela. Enquanto isto, Koetsier e Bergmans (2005) reuni 35 artigos sobre a influência da matemática sobre o desenvolvimento da teologia e da religião.

A importância e ubiquidade da matemática para os multifacetados aspectos da cultura humana é, então, um forte motivo para que o aluno tenha contatos diretos com grandes obras matemáticas. Uma maneira de fazer isto seria através de disciplinas sobre a história da matemática centradas na leitura e análise de fontes históricas. Uma outra forma de alcançar o referido desiderato seria a incorporação de textos históricos no ensino da matemática. Abordaremos essa opção no que segue, mas antes mencionaremos outro aspecto do ensino da matemática relacionado a cultura. 


\section{Diversidade Cultural e Equidade}

O reconhecimento do aspecto cultural da matemática nos leva a considerar mais alguns objetivos pedagógicas do sistema escolar, a saber, a apreciação da diversidade cultural e a equidade de pessoas de diversas culturas. É de convir que qualquer sociedade grande é composta de grupos distintos com interesses parcialmente conflitantes que podem ameaçar a sua unidade e pôr em risco os direitos básicos das pessoas de um ou mais desses grupos vis-àvis os outros componentes da coletividade social. As tenções podem ser até exacerbadas em sociedades multiculturais como a brasileira. A história da matemática poderá ajudar a combater essas tenções por mostrar que a matemática representa uma herança cultural de todos nós, à qual todos têm contribuído. De fato, uma das motivações do surgimento da etnomatemática, um ramo da história da matemática, foi exatamente a preocupação com a inclusão social no meio escolar.

Nesse sentido, a leitura de textos históricos poderá ser um recurso poderoso na consecução de objetivos relacionados à diversidade e à equidade porque implica que haja um diálogo virtual entre o leitor e o autor da obra. Deve ser claro, porém, que queremos dizer por 'leitura' não simplesmente uma leitura superficial, mas uma leitura crítica, utilizando todas as técnicas hermenêuticas que usaríamos para analisar qualquer outro texto de qualquer outro domínio do saber, incluindo uma apreciação do milieu histórico-social da sua criação. Ao fazer isto, criamos laços sociais de nível pessoal com o autor e, ao fazer isto com autores de culturas diversos da nossa, diminuímos as tenções oriundas da diversidade.

As considerações aqui apresentadas em relação à diversidade cultural são obviamente aplicáveis, mutatis mutandis, a questões de gênero.

\section{Conhecimento}

Como vimos, então, a leitura de textos históricos na sala de aula é um mandato imperioso para os que querem ter um conhecimento da cultura humana e, assim, julgamos que as referidas leituras devem fazer parte do currículo escolar. Também vimos que podemos efetuar tais leituras em duas maneiras principais, a saber, em disciplinas dedicadas à história da matemática ou embutidas nas próprias disciplinas de conteúdo matemático. Voltaremos a nossa atenção agora sobre a segunda das mencionadas alternativas, pois a incorporação de 
fontes históricas na sala de aula de matemática poderá ser de muito serventia ao aluno nas suas tentativas de construir o conhecimento matemático.

Para ver como isso procede, precisamos nos delongar um pouco sobre a natureza do conhecimento. O problema do conhecimento é um problema complexo e sutil, envolvendo relacionamentos dialéticos entre o indivíduo, o outro e o objeto. Não será procedente entrar nos detalhes de tudo isto agora, mas pelo menos podemos afirmar, de forma simplificada, que os três aspectos que destacamos implicam que, em todo ato de conhecimento, haja alguém que ativamente produz o conhecimento, que o mesmo é feito como produto social e que é feito perante dum mundo que se revela ao conhecedor. No que segue, tentaremos explanar o que está envolvido em cada um desses três aspectos da construção do conhecimento e o papel facilitador que a leitura de textos históricos pode fazer em cada um deles.

\section{O Aluno Ativo}

Antigamente se considerava, em geral, o conhecimento como algo que acontecia ao sujeito. Neste sentido, o aluno era suposto análogo a um vaso, que iria ser preenchido com conhecimento pelo professor. Foi talvez a "revolução copernicana"9 de Immanuel Kant (17241804) que reverteu esse conceito de forma sustentável pela primeira vez. Para Kant, a mente tem uma determinada estrutura que ela usa para formar e ordenar o material amorfo que recebe dos sentidos. A ideia foi desenvolvida em termos psicológicos por Jean Piaget ${ }^{10}$ (18961980). Para ele, o conhecimento consiste na assimilação (incorporação) de novos itens a uma estrutura mental já existente e na acomodação da estrutura a novos itens por mudanças na dita estrutura. As consequências epistemológicas e pedagógicas, especialmente no contexto da Educação Matemática, da teoria construtivista foram avançadas ainda mais no construtivismo radical $^{11}$ de Ernst von Glasersfeld e os pesquisadores associados a ele. Nessa teoria a necessidade da construção ativa do conhecimento pelo conhecedor (o aluno) é enfatizado.

Segundo o construtivismo, então, todo conhecimento é construído e isso acontecerá sempre que houver conhecimento, independentemente da metodologia de ensino adotada. Não obstante, o ensino será mais eficaz, ou menos eficaz, dependendo da sua consonância com a natureza do conhecimento. Assim, o ensino assentado sobre explicações verbais do professor

\footnotetext{
${ }^{9}$ Ver Kant (1968); em português, Kant (2004).

${ }^{10}$ Ver Piaget (1970a); original em inglês, Piaget (1970).

${ }^{11}$ Ver Fossa (2014), em português, ou Fossa (2019a), em inglês.
} 
não proporciona ao aluno muito incentivo de se investir no processo construtivo necessário para a obtenção de um bom nível ${ }^{12}$ de conhecimento. Nesse modo de ensino, o livro texto tende a ser apenas um repositório fossilificado do discurso do professor, de que o aluno apanha modelos estáticos para a resolução rotineira dos exercícios e de que obtém pouco preparo para enfrentar problemas novos. Uma aprendizagem mais profunda fica, assim, inteiramente condicionada à casualidade de um interesse maior da parte do próprio aluno.

Tudo muda, porém, quando se usa fontes históricas na sala de aula. Isto sucede porque, tipicamente, o professor não explica o texto ao aluno, mas exige que o aluno o explora e tenta decifrar o conteúdo dele. Para tanto, o aluno é automaticamente colocado numa situação em que sucesso -até sucesso parcial - é somente alcançado com um aumento de esforço pessoal que ele desempenha no deciframento de um texto escrito segundo padrões diferentes dos de textos contemporâneos. Nesse sentido, tanto o próprio texto histórico, quanto a metodologia de ensino associada ao seu uso na sala de aula, proporcionam ao aluno oportunidades de construir seu conhecimento de forma ativa e consciente, visto que o processo hermenêutico de interpretação de textos históricos implica no engajamento com o texto e envolve naturalmente o desenvolvimento de habilidades metacognitivas.

Disto, deve ser claro que a fonte histórica a ser usada na sala de aula precisa ser escolhida criteriosamente para atender aos objetivos pedagógicos do contexto do seu uso. Em especial, é necessário selecionar textos que coadunam com a base cognitiva do aluno e utilizar metodologias que levam o aluno a desenvolver as suas habilidades hermenêuticas, sobretudo quando as suas competências de leitura estão pouco evoluídas.

\section{Construção Social}

Visto que o construtivismo é pautado sobre a construção de estruturas mentais e centra muita da sua atenção na atividade do indivíduo, seus partidários têm uma tendência muito grande a esquecer que a aprendizagem - isto é, a própria construção do conhecimento - é um projeto social ${ }^{13}$. Enquanto o indivíduo precisa construir suas próprias estruturas mentais, ele só pode fazer isto em conjunção com o outro, pois o outro é necessário para que o indivíduo

\footnotetext{
${ }^{12}$ Ver, por exemplo, Skemp (1976).

${ }^{13} \mathrm{O}$ construtivismo social, embora esteja presente na obra de Piaget, obteve reconhecimento geral através da obra do psicólogo russo Lev Vygotsky (1896-1934). Atualmente se constitui, em várias formas, um elemento importante de várias teorias educacionais.
} 
possa apropriar a ciência (no sentido mais lato) já desenvolvida pelo homem. De fato, o indivíduo nunca é um solitário, mas sempre se acha inserido dentro de uma cultura e, em qualquer determinado momento da sua vida, sua base cognitiva é dependente das relações dialéticas que ele se mantém com seu ambiente social. As referidas relações são dialéticas porque o homem não somente apropria a cultura da sociedade ambiente, mas também contribui à continuidade da mesma e às maneiras em que ela se modifica no tempo.

Nesse sentido, a leitura e análise de textos históricos é uma maneira de dialogar com grandes inovadores da cultura matemática. Destaca-se a origem e propósito dos conceitos abordados, a argumentação usada pelo autor e o desenvolvimento dos métodos adotados. Leituras mais sofisticadas podem incluir oportunidades perdidas e comparações diacrônicas. Mas, em qualquer caso, a análise do texto levará o aluno a uma compreensão mais profunda da matemática por enriquecer seu conhecimento de abordagens alternativas, aprofundar seu entendimento de conceitos matemáticos e proporcionar uma apreciação maior das interconexões entre as várias partes da matemática, bem como da matemática com outras partes da nossa cultura. Ao proceder dessa maneira, o aluno constrói suas próprias estruturas mentais enquanto apropria, de forma intensa e consciente, a cultura matemática.

Dependendo da metodologia de ensino usado, o diálogo que o aluno mantém com o outro ao ler textos históricos não se limita ao diálogo com o(s) autor(es) do texto e outros atores históricos, mas também inclui seus pares contemporâneos, pois a própria análise é um ato social. Isto pode ser enfatizado por fazer a análise cooperativamente, em pequenos grupos por exemplo, e por colocá-la a prova diante do grupo maior. Os resultados podem ser muito enriquecedores para o aluno.

Ilustro isto com dois exemplos que aconteceram em aulas por mim ministrados. Ao ler Os Elementos de Euclides, os alunos estranharam a frase "um número mede outro" para se referir à divisão de um número por outro. Isto levou a uma consideração do papel da geometria face à aritmética, bem como o papel da demonstração racional na sociedade grega antiga e a sua incorporação na matemática. Noutra aula, os alunos leram partes do já mencionado Euler (2017), onde se encontra dois juízos distintos sobre números primos, no primeiro dos quais a unidade é incluída e no segundo excluída. Isto gerou uma discussão sobre o conceito de número primo e seu lugar na teoria da aritmética. Pesquisaram em livros modernos de álgebra, mas não ficaram satisfeitos com a razão ali apresentada para a exclusão 
da unidade dos primos (que 1 é o elemento neutro da multiplicação). Era só quando atinaram com o fato de que incluir a unidade entre os primos implicaria na perda da unicidade da Teorema Fundamental da Aritmética (decomposição em números primos) que entenderam o problema - e apreciaram que o desenvolvimento de uma teoria matemática envolve, às vezes, escolhas entre desideratos excludentes. Tais experiências de aprendizagem não somente ajudam o aluno a entender mais profundamente os conceitos matemáticos em jogo, mas também promovem uma apreciação maior da matemática como um produto cultural do homem.

\section{O Mundo Matemático}

É notável que o homem não somente se acha numa cultura, mas também se acha num mundo. Temos uma forte tendência de conceitualizar o mundo como algo externo e independente de nós e, consequentemente, pensamos no relacionamento nosso com o mundo como consistindo de relações externas entre seres individualizados independentes uns dos outros, cada um dos quais pode afetar outros através de forças físicas. Tanto a filosofia, quanto a ciência (especialmente a física quântica), porém, tem desmentido a referida tendência por postular a importância das relações internas entre todas as coisas de tal forma que nós e o mundo não somos independentes, mas mutuamente constituídos. Aqui, faremos apenas algumas breves considerações, partindo da fenomenologia de Martin Heidegger (1889-1976).

Segundo a fenomenologia, os seres do mundo se revelam ao homem. Mas, só podem fazer isto através da nossa apropriação deles pela linguagem. Nesse sentido, os referidos objetos do mundo são constituídos pelo homem e para o próprio homem. Dessa forma, o mundo é, ao mesmo tempo, maleável e recalcitrante às ações humanas. O mesmo acontece com os objetos matemáticos, que são objetos abstratos e não-físicos. Por um lado, os matemáticos inventam os objetos matemáticos, pois eles resultam da atividade matemática como um produto humano; por outro lado, todo matemático tem a sensação de que está descobrindo fatos matemáticos. Essa dialética entre a invenção e a descoberta é tão essencial ao conhecimento matemático quanto o é a dialética entre a independência e a dependência ao conhecimento de objetos físicos. Nos dois casos, o ato de apropriação é caraterizado pela teorização ${ }^{14} \mathrm{e}$, portanto, é somente através da teorização que conhecimento genuíno é

\footnotetext{
${ }^{14}$ Para mais detalhes ver Fossa (2012).
} 
construído. Em termos pedagógicos, a posição fenomenológica implica que o conhecimento genuíno não se limita à simples incorporação de estruturas mentais do outro aos seus esquemas mentais, pois isto condena o aluno a viver num mundo alienado. É só com a teorização sobre o mundo, seja ele o mundo físico ou o mundo matemático, que o aluno consegue fazer suas próprias construções e apropriar o mundo a si, fazendo-o o seu.

Uma maneira eficaz de ajudar o aluno a obter o conhecimento genuíno é através da leitura de fontes históricas na sala de aula. O texto histórico contém um relato de um ato original de apropriação e, ao fazer uma exegese hermenêutica do texto, o aluno poderá recapturar e reviver o referido ato original de apropriação, fazendo-o o seu. A re-vivência do ato criativo original coloca, de fato, o aluno às fronteiras da pesquisa matemática num ponto do passado e faz com que ele participa no processo de criação. Sua participação, contudo, é privilegiada, pois ele é consciente do fato de que sua experiência é uma re-vivência e assim não somente recria, junto com o autor original, uma parcela da matemática, mas também teoriza sobre o mesmo à luz de conhecimentos mais modernos. ${ }^{15}$ Foi exatamente isto o que aconteceu com os já mencionados alunos que precisavam, primeiro, decidir junto com Euler, se a unidade fosse, ou não, um número primo e, depois, decidir se o juízo de Euler era acertado, ou não, à luz de outras considerações.

\section{Considerações Finais}

Com o desenvolvimento da história da matemática como uma importante tendência da Educação Matemática, a história passou a desempenhar vários papéis pedagógicos interessantes na sala de aula. Alguns deles, como o uso da história para aguçar a motivação do aluno, foram usados há muito tempo, embora de forma mais tímida do que é feito atualmente, enquanto outros, como o uso da história para aprimorar as habilidades de leitura e de escrita do aluno, são de data mais recente. Igualmente a qualquer outra estratégia pedagógica, esses usos da história da matemática não resolvem todos os problemas do ensino da matemática, nem funcionam da mesma forma para todos os alunos. Não obstante, têm se mostrado instrumentos muito valiosos na busca de um ensino eficaz de qualidade. Nesse sentido, devem fazer parte do repertório pedagógico de todos os professores de matemática.

\footnotetext{
${ }^{15}$ Para mais detalhes, ver Fossa (2016).
} 
O presente trabalho, no entanto, não tem adentrado na utilização desses importantes instrumentos para o ensino de matemática com a história da matemática. Antes, temos procurado mostrar a posição privilegiada da leitura de textos históricos na sala de aula. Para tanto, expusemos dois argumentos que ressaltem a importância desse procedimento para o ensino da matemática, sendo que o primeiro se assenta sobre a conceitualização da matemática como parte da herança cultural do homem e o segundo sobre a natureza do conhecimento.

Podemos resumir o primeiro argumento da seguinte maneira: a matemática é uma das mais importantes partes da cultura humana no sentido de que permeia quase todas as outras partes dessa cultura; assim, na medida em que a educação deve levar o aluno a apropriar a cultura humana para que alcançasse uma vida rica e plena, o aluno deve ter contato direto e intenso como os produtos (isto é, as fontes históricas) da cultura matemática. A conclusão aqui é diferenciada daquela que é feita para outros usos da história da matemática como um instrumento pedagógico da Educação Matemática, pois os referidos argumentos mostram a eficácia das várias modalidades e proponham a sua adoção pelo professor quando apropriado. O presente argumento, em contraste, conclui que, da mesma forma em que é necessário que o aluno tenha a experiência de confrontar diretamente grandes obras de literatura, é necessário que ele também tenha a experiência do confronto direto com grandes obras de matemática.

$\mathrm{O}$ segundo argumento que abordamos aqui se estrutura sobre a natureza tripartida do conhecimento, mostrando como a leitura de fontes históricos se adequa $(i)$ à atividade construtiva do conhecimento, (ii) à natureza social do conhecimento e (iii) à dialética da apropriação do objeto matemático. Desta forma, a leitura de textos históricos leva o aluno a fazer teorizações sobre a matemática o que implica na construção de matemática genuína.

Os dois argumentos são razões cogentes para a inclusão de leituras de textos históricos na sala de aula.

\section{Referências}

Abdounur, Oscar João. (2002). Matemática e música: O pensamento analógico na construção de significados. São Paulo: Escrituras Editora.

Adler, Mortimer. (1961). Great Ideas from the Great Books. New York: Washington Square Press.

Almeida, Manoel de Campos. (A aparecer). Elementos de cálculo diferencial e integral: o "Granville". Volume 3 da Coleção Cacoá. Campina Grande: Editora da UEPB. 
Erickson, Glenn W., e Fossa, John A. (2006). A linha dividida: Uma abordagem matemática à filosofia platônica. Rio de Janeiro: Relume Dumará.

Euclid. (1956). The elements. Trad. de T. L. Heath. New York: Dover.

Euclides. (2009). Os elementos. Trad. de Irineu Bicudo. São Paulo: Editora da UNESP.

Euler, Leonhard. (2017). Tratado sobre a teoria dos números em XVI capítulos. Trad. de John A. Fossa. Natal: Editora da UFRN. Ebook disponível em: www.repositorio.ufrn.br. Consulta em 04/10/2019.

Euler, Leonhard. (2017a). Sobre números amigáveis. Trad. de John A Fossa, Sarah Mara Silva Leôncio e Fabricio Possebon. Natal: Editora da UFRN. Ebook disponível em: www.repositorio.ufrn.br. Consulta em 04/10/2019.

Euler, Leonhard. (1849). De numeris amicabilibus. Commentationes arithmeticae 2, p. $627-$ 636.

Euler, Leonhard.(1750). De numeris amicabilibus. Opuscula varii argumenti 2, p. 23-107.

Euler, Leonhard. (1774). De numeris amicabilibus. Nova acta eruditorum, p. 267-269.

Fossa, John A. (2019). O status epistemológico do conhecimento matemático. Disponível em: https://www.researchgate.net/publication/335682130 O Status Epistemologico do_Conhecimento_Matematico. Consulta em 04/10/2019.

Fossa, John A. (2019a). Intuitionist theory of Mathematics Education. Disponível em: https://www.researchgate.net/publication/331438081_Intuitionist_Theory_of_Mathem atics_Education. Consulta em 04/10/2019.

Fossa, John A. (2016). Conhecimento como apropriação e a história da matemática como agente de cognição. In Emmanuel Ribeiro Cunha, Marta Genú Soares e Pedro Franco de Sá (Orgs.). Formação de Professor: Teorias e Práticas Cotidianas. Belém: Editora da UEPA, p. 15-32.

Fossa, John A. (2014). Teoria intuicionista da Educação Matemática. 2a . ed. São Paulo: Editora Livraria da Física.

Fossa, John A. (2012). Heidegger, Hebel e Educação Matemática. Revista Educação Matemática em Foco. Vol. 1, n. 1 (janeiro/junho), p. 41-51.

Fossa, John A. (2006). Recursos pedagógicos para o ensino da matemática a partir das obras de dois matemáticos da antigüidade. In: Iran Abreu Mendes, John A. Fossa e Juan E. Nápoles Valdés (orgs.). A história como um agente de cognição na Educação Matemática. P. 137-182. Porto Alegre: Sulina.

Fossa, John A. (1998). Historical ways of teaching mathematics. In: Proceedings of the first ICMI East Asain Conference on Mathematics Education. V. 3. p. 423-428. Chungju (Korea).

Fossa, John A., e Erickson, Glenn W. (2014). The Oedipus myth as mathematical allegory. Revista brasileira de história da matemática, v. 14, n. 29, p. 31-58.

Gamwell, Lynn. (2016). Mathematics and art: A cultural history. Princeton: Princeton University Press. 
Granville, William Anthony, e Smith, Percey F. (1904). Elements of the differential and integral calculus. Boston: Ginn \& Company.

Granville, W.A., Smith, P. F., e Longley, W. R. (1961). Elementos de cálculo diferencial e integral. Trad. De J. Abdelhay. Rio de Janeiro: Editora Científica.

Grugnetti, Lucia, e Rogers, Leo. (2000). Philosophical, multicultural and interdisciplinary issues. In: John Fauvel e Jan van Maanen, (Eds.). History in Mathematics Education. Dordrecht: Kluwer.

Hill, C. O. (2002). On Husserl's mathematical apprenticeship and philosophy of mathematics. In: Anna-Teresa Tymieniecka (Ed.). Phenomenology world-wide. Analecta husserliana (The Yearbook of Phenomenological Research), vol. 80. Doddrecht: Springer.

Hofstadter, Douglas R. (1980). Gödel, Escher, Bach: An eternal golden braid. New York: Vintage Books.

Kant, Immanuel. (2004). Crítica da razão pura. Tradução de Afonso Bertagnoli. Disponível em <http://www.ebooksbrasil.org/eLibris/razaopratica.html>. Consulta em 19/09/2019.

Kant, Immanuel. (1968). Kritik der reinen Vernunft. In: Kants Werke (Vol. III). Berlin: Walter de Gruyter \& Co. [Original 1788.]

Joseph, George Gheverghese. (1991). The crest of the peacock. Princeton: Princeton University Press.

Koetsier, T., e Bergmans, L. (2005). (Eds.) Mathematics and the divine: A historical study. Amsterdam: Elsevier.

Parsons, Charles. (1983). Mathematics in philosophy. Ithaca (NY): Cornell University Press.

Piaget, Jean. (1970). Genetic epistemology. New York: Columbia University Press.

Piaget, Jean. (1970a). Epistemologia genética. Petrópolis: Vozes.

Skemp, Richard R. (1976). Relational understanding and instrumental understanding. Mathematics teaching, 77, p. 20-26.

The Rhind mathematical papyrus. (1927). Trad. de A. B. Chace e H. P. Manning. Oberlin: The Mathematical Association of America.

Autor

John A. Fossa, Ph.D.

Doutorado em Educação Matemática pela Texas A\&M University System(1994). Mestrado em Filosofia pela Fordham University(1974). Graduação em Filosofia pela College Of The Holy Cross(1972). Docente aposentado da Universidade Federal do Rio Grande do Norte. Atualmente é Professor pesquisador Visitante da Universidade Estadual de Campina Grande (PB). Tem experiência na área de Matemática, com ênfase em História da Matemática. Atuando principalmente nos seguintes temas: Educação Matemática, Intuicionismo, Construtivismo Radical. Mais informacões no Currículo Lattes: http://lattes.cnpq.br/2466525106349625. ORCID: http://orcid.org/0000-0002-7957-6656. E-mail: jfossa03@gmail.com. 